\title{
Nitrous Oxide Versus Lidocaine for Pain Relief During Episiotomy Repair: A Randomized Trial
}

\author{
Nahid Javadifar ${ }^{1}$, Azam Honarmandpour ${ }^{2 *}$, Zahra Abbaspoor ${ }^{1}$, Amal Saki Malehi ${ }^{3}$
}

\begin{abstract}
Objectives: Since pain reduction is an important concern in childbirth, this study was designed to evaluate the effects of nitrous oxide in comparison with lidocaine on pain relief, during episiotomy repair in primiparous women.

Materials and Methods: A prospective randomized controlled trial method was used in this study and 120 term pregnant women were recruited. The intervention group received nitrous oxide 2 minutes before starting episiotomy repair, until the end of the procedure. The control group received $5 \mathrm{~mL}$ of lidocaine (2\%) before starting the episiotomy. The results of the 2 groups were compared with regard to pain intensity using a visual analogue scale (VAS). Mann-Whitney, student's $t$ test and chi-square test were used to analyze the data.

Results: Sixty women were studied in each group. Nine participants (15\%) in nitrous oxide group, as opposed to 23 participants $(38.4 \%)$ in lidocaine group had moderate, severe or extremely severe pain intensity $(P$ value $=0.005)$. In terms of satisfaction level, there was no significant difference between 2 groups $(P$ value $=0.713)$.

Conclusion: The results of this study showed that pain intensity in the nitrous oxide group was significantly lower than that in the lidocaine infiltration group. Application of nitrous oxide at least 2 minutes before repair may be an effective method for pain management in episiotomy repair.

Keywords: Nitrous oxide, Episiotomy, Lidocaine, Pain
\end{abstract}

\section{Introduction}

For nearly 80 years, episiotomy has been routinely performed but there is no strong evidence of its effectiveness, hence it has remained controversial (1). The prevalence of episiotomy varies from $10 \%$ in developed countries (Sweden) to $100 \%$ in developing countries (Taiwan) (2,3). Episiotomy repair requires anesthesia, and lidocaine is usually used for this purpose (4). Infiltration of lidocaine can cause accidental intravascular injection and sensation of burning pain, and edema due to insertion of needle (5). Today, non-injectable methods have a new place in medicine to reduce pain. Nitrous oxide (combination of $\mathrm{N}_{2}$ and $\mathrm{O}_{2}$ with the equal ratio of $50 \%$ ) has strong analgesic effects (equivalent to $15 \mathrm{mg}$ of subcutaneous morphine) and is frequently used in childbirth and emergencies by medical professionals (6).

Studies have shown that nitrous oxide or entonox can be utilized as an analgesic agent in obstetrics, cancers intraarticular injections, sigmoidoscopy, colonoscopy, and biopsy, (7) and it appears to provide effective analgesia for many parturient women $(7,8)$. However, in a study, it was not effective in reducing pain in shoulder joint dislocation repair (9). The peak effect of nitrous oxide occurred within 30 seconds after inhalation and persisted for about 1 minute and gradually decreased in
5 minutes after inhalation (10). Nitrous oxide induces the release of endorphins and at higher concentrations, they provide analgesia, as well as skeletal and muscular relaxation (6). Unfortunately, despite recommendation against the routine use of episiotomy, this procedure is performed for the majority of primiparous women in developing countries $(3,11)$. There are a considerable number of investigations about post perineal repair pain relief after episiotomy $(12,13)$ but there are few reports on the effectiveness of analgesia during perineal suturing (14). Since pain is an important concern in childbirth and using episiotomy is inevitable in some cases, this randomized clinical trial study was conducted to evaluate the effectiveness of nitrous oxide in comparison to lidocaine on pain intensity during episiotomy repair in primiparous women.

\section{Materials and Methods}

Study Design and Participants

This prospective randomized controlled clinical trial was conducted on primiparous women who attended a referring academic hospital in the southwest of Iran (Shushtar). Inclusion criteria were: Primipara women between 39 to 42 weeks of gestation according to sonographic findings or last menstrual period date, 
mother's age in 18 to 35 years, singleton gestation, uncomplicated pregnancy, cephalic presentation and first trimester body mass index (BMI) in range of 18.5 to $30 \mathrm{~kg} /$ $\mathrm{m}^{2}$. Women were excluded if they had operative delivery, perineal laceration or large episiotomy, intact perineum and previous sensitivity to local anesthesia or nitrous oxide. Using of opioids, inhalation or pudendal block for labor pain relief is not common in our institutions.

\section{Setting and Sampling}

The primary outcome measure of the present study was pain intensity during episiotomy repair and secondary outcomes were satisfaction with the anesthesia and side effects of $\mathrm{N}_{2} \mathrm{O}$. The power of the study was calculated based on a previous study in which mean pain intensity during perineal repair was $4.24 \pm 2.78$ (14). Based on a study potency of $80 \%$, an alpha of 0.05 , parameters of previous studies and attrition of $30 \%$, the sample size was determined as 120 women (60 women in each group). Women were allocated to each group by block randomization method in a 1:1 ratio using a randomized computer-generated list. The allocation arm was written on cards that were sealed in sequentially numbered opaque envelopes. The envelopes were opened after the enrolled women had completed the basic evaluations.
Groups were compared with regard to pain intensity using a visual analogue scale (VAS) (Figure 1). According to this scale, zero indicates no pain, 1 to 3 mild, 4 to 6 moderate, 7 to 9 severe and 10 expresses extremely severe pain (15).

Participants received explanation and were fully informed about the procedures. Confounding variables were matched for 2 groups which included incision length, type of incision, type of incision repair, and number of vaginal examinations. The procedure of episiotomy and repair was performed by one of the midwives of the institute (A.H). She was there 6 hours per day, 4 days per week in different working time from July to September 2015. All episiotomies were performed as mediolateral episiotomy after fetal head crowning at the top of the contraction. Data gathering was done by another staff, unaware of the type of analgesia. In the delivery room after placental delivery, the control group received routine care and $5 \mathrm{ml}$ of lidocaine (2\%) along the edges of the episiotomy with frequent aspirations before starting the episiotomy repair. Women in the intervention group received routine care and inhaled nitrous oxide deeply and slowly 2 minutes before starting the episiotomy repair until the end of the procedure as they were trained. Entonox mask was worn on the mother's face for repeated inhalation, according to the respiration model of "deep inhale- pausing- slow exhale-

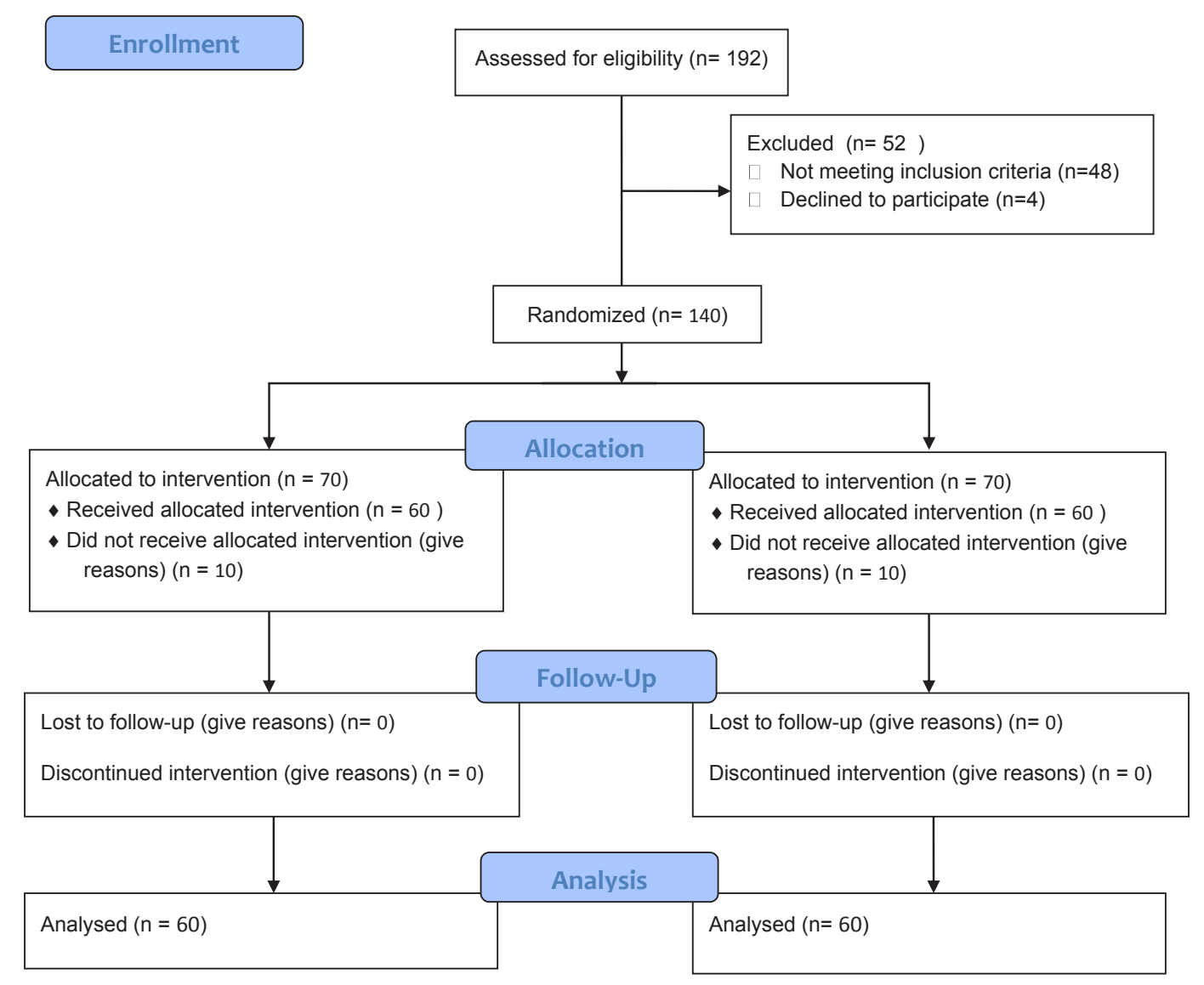

Figure 1. Flow Diagram of Recruitment and Retention of Participants in the Study. 
rest". The women were free to use nitrous oxide whenever they liked. In all cases, episiotomies were repaired with routine technique. In Iran, mediolateral episiotomy is a common procedure especially in primipara women and the absorbable catgut used for episiotomy repair. The duration of nitrous oxide use, respiratory rate, pulse rate, blood pressure and $\mathrm{O}_{2}$ saturation were recorded by a staff before, during and after episiotomy repair. Pain intensity was measured using VAS after repair in postpartum care unit. In VAS measurement scale, number 5 was deemed as acceptable pain intensity. The questionnaire and checklist were designed based on scientific resources and 10 faculty members confirmed the content validity of the tools.

Mother's satisfaction in 2 groups was evaluated using the scale of completely satisfied, satisfied, unsatisfied, and completely unsatisfied and adverse effects of $\mathrm{N}_{2} \mathrm{O}$ were assessed in the intervention group.

\section{Statistical Analysis}

Data analysis was performed using SPSS version 16.0. Normality of the quantitative variables in the groups was not confirmed using Kolmogorov-Smirnov test. The Mann-Whitney U test was used to compare nonparametric variables and the $t$ test was performed for continuous parametric variables (neonatal birth weight and head circumference). The chi-square test was performed for categorical data and the differences were considered statistically significant if $P$ value was less than 0.05 .

\section{Results}

Both groups showed no statistical significant difference in maternal age, education, BMI, neonatal birth weight, head circumference, duration of second and third stages of labor and gestational age (LMP and sonography). The duration of episiotomy repair was significantly lower in $\mathrm{N}_{2} \mathrm{O}$ group (Table 1). There was no significant difference between the 2 groups in terms of clinical properties (pulse rate, respiratory rate, blood pressure and $\mathrm{O}_{2}$ saturation) and other conditions such as, rupture of amniotic membrane, requiring labor induction, participation in childbirth preparation classes, exercises and perineal massage during pregnancy $(P$ value $>0.05)$.

None of the women in the intervention group needed lidocaine in addition to $\mathrm{N}_{2} \mathrm{O}$ to relief the pain, all participants in the intervention group tended to use $\mathrm{N}_{2} \mathrm{O}$ until the end of perineal repair.

The rate of the adverse effects in the $\mathrm{N}_{2} \mathrm{O}$ group showed that 20 patients $(33.3 \%)$ had no special side effects, 26 patients $(43.3 \%)$ had dizziness, 7 patients (11.7\%) had dry mouth (xerostomia), and 7 cases $(11.7 \%)$ showed drowsiness. The adverse effects were temporary and they disappeared after termination of the inhalation. Pain intensity in the $\mathrm{N}_{2} \mathrm{O}$ group using VAS was significantly lower compared with the lidocaine group $(P$ value $<0.005)$ (Table 2). There was no significant difference between the 2 groups in terms of satisfaction level $(P$ value $=0.713)$ (Table 3).

\section{Discussion}

The use of $\mathrm{N}_{2} \mathrm{O}$ in the process of labor and postpartum is less considered in developing countries (16), especially for episiotomy or perineal repair. Evidences suggest that there is a considerable pain during perineal suturing but the amount and intensity of pain women experience during this procedure is not well understood (17). $\mathrm{N}_{2} \mathrm{O}$ is a nonflammable, tasteless, odorless gas and the intermittent use of $50 \% \mathrm{~N}_{2} \mathrm{O}$ in oxygen which is most widely adopted, probably optimizes patient safety (17). The statistical significant findings of this study indicate that $\mathrm{N}_{2} \mathrm{O}$ may be effective in reducing pain intensity during episiotomy repair when compared with Lidocaine $(P$ value $=0.005)$. The study of Kindberg et al (18) showed that lidocaine

Table 1. Demographic and Labor Characteristics

\begin{tabular}{|c|c|c|c|}
\hline Variables & $\mathrm{N}_{2} \mathrm{O}(\mathrm{n}=60)$ & Lidocaine $(n=60)$ & P Value \\
\hline Maternal age (y) & $23 \pm 4.26$ & $23.25 \pm 4.28$ & 0.740 \\
\hline Education, No. (\%) & & & 0.125 \\
\hline Illiterate & $1(1.7)$ & $3(5)$ & \\
\hline High school diploma & $31(51.7)$ & $31(51.7)$ & \\
\hline Diploma & $20(33.3)$ & $11(18.3)$ & \\
\hline University & $8(13.3)$ & $15(25)$ & \\
\hline Body mass index $\left(\mathrm{kg} / \mathrm{m}^{2}\right)$ & $23.08 \pm 3.68$ & $23.62 \pm 2.99$ & 0.891 \\
\hline Birth weight (g) & $3242.500 \pm 249.715$ & $3270.833 \pm 329.77$ & 0.597 \\
\hline Gestational age (LMP) & $40.0 \pm 2.5$ & $40.0 \pm 2.1$ & 0.996 \\
\hline Gestational age (Sono) & $40.0 \pm 2.5$ & $40.0 \pm 2.0$ & 0.695 \\
\hline Neonatal head circumference $(\mathrm{cm})$ & $34.15 \pm 0.98$ & $34.23 \pm 0.95$ & 0.654 \\
\hline Duration of second stage of labor (min ) & $47.50 \pm 25.47$ & $46.50 \pm 33.05$ & 0.309 \\
\hline Duration of third stage of labor ( $\mathrm{min}$ ) & $7.6 \pm 8.7$ & $8.1 \pm 9.9$ & 0.061 \\
\hline Duration of episiotomy repair (min) & $15.3 \pm 7.1$ & $17.2 \pm 8.5$ & 0.001 \\
\hline
\end{tabular}

Value are expressed as mean $\pm \mathrm{SD}$; means were compared by Mann-Whitney $U$ test or $t$ test (for continuous data); categorical data were compared by $\chi^{2}$. 
Table 2. Pain Severity Measurement During Episiotomy Repair Between Nitrous Oxide and Lidocaine Groups Using VAS ${ }^{a}$

\begin{tabular}{lcc}
\hline Pain Severity & $\begin{array}{c}\mathbf{N}_{\mathbf{2}} \mathbf{O} \\
\mathrm{n}=\mathbf{6 0}(\%)\end{array}$ & $\begin{array}{c}\text { Lidocaine } \\
\mathrm{n}=60(\%)\end{array}$ \\
\hline Mild & $51(85)$ & $37(61.7)$ \\
Moderate & $9(15)$ & $18(30)$ \\
Severe & $0(0)$ & $4(6.7)$ \\
Extremely severe & $0(0)$ & $1(1.7)$ \\
\hline
\end{tabular}

a $P=0.005$.

Table 3. Satisfaction Rate During Episiotomy Repair in 2 Groups of Nitrous Oxide and Lidocaine ${ }^{a}$

\begin{tabular}{lcc}
\hline Satisfaction Rate & $\begin{array}{c}\mathbf{N}_{\mathbf{2}} \mathbf{O} \\
\mathbf{n}=\mathbf{6 0}(\%)\end{array}$ & $\begin{array}{c}\text { Lidocaine } \\
\mathbf{n}=60(\%)\end{array}$ \\
\hline Unsatisfied & $0(0)$ & $1(1.7)$ \\
Satisfied & $32(53.3)$ & $34(56.7)$ \\
Completely satisfied & $28(46.7)$ & $25(41.7)$ \\
\hline
\end{tabular}

a $P=0.713$.

was more effective in reducing pain intensity during episiotomy repair compared with acupuncture. In a clinical trial published by Berlit et al. (19), the difference between $\mathrm{N}_{2} \mathrm{O}$ and lidocaine in reducing pain during the repair of genital lacerations was not statistically significant $(P$ value $=0.69)$, which was not consistent with the findings of the present study. The findings of our study are similar to those reported by Franchi et al who compared topical Emla cream $(\mathrm{n}=31)$ with injection of mepivacaine $(\mathrm{n}=$ 30) for perineal repair. They showed that pain reduction and maternal satisfaction were higher in the Emla group (20). Although some studies have indicated that the analgesic effect of $\mathrm{N}_{2} \mathrm{O}$ can be used for pain relief during the first, second, and third stages of labor and postpartum procedures such as perineal repair, manual removal of placenta or uterine curettage (21). The majority of the related studies suggest infiltrative anesthesia as an effective method for reducing pain during episiotomy suturing. Some evidences also suggest the administration of $\mathrm{N}_{2} \mathrm{O}$ in addition to lidocaine for better pain control (22), in contrast, some investigations revealed that pain relief with $\mathrm{N}_{2} \mathrm{O}$ does not need additional medication (17). There are no considerable clinical trials about pain management during episiotomy repair. In the present study, none of the participants in either group needed additional anesthesia and satisfaction of the used method was the same between 2 groups. The chi-square test results did not show significant difference between the $\mathrm{N}_{2} \mathrm{O}$ and lidocaine groups $(P$ value $=0.173)$. In an investigation done by Berlit et al, the addition of prilocaine (31\% in study group and $2 \%$ in control group) was necessary and the satisfaction does not significantly differ between the 2 groups (19). Gutton et al (23) reported an improvement in analgesia and maternal satisfaction when ropivacaine versus lidocaine was used for perineal infiltration postepisiotomy and in the study of Kindberg et al (18) satisfaction with acupuncture was significantly lower than lidocaine $(P$ value $=0.01)$. The most prevalent side effect in this study was dizziness. In the present study, all side effects were transient and relieved after the termination of inhalation. The study conducted by Berlit et al showed that in $45 \%$ of the cases, entonox had no side effects, and in the rest of the cases, the side effects of entonox included dizziness (35\%), euphoria (31\%), and nausea (4\%), all of which were transient and this is consistent with the result of this study (19). Similar studies have reported side effects such as dry mouth, dizziness, drowsiness and nausea $(24,25)$.

In the $\mathrm{N}_{2} \mathrm{O}$ group, the duration of episiotomy repair was significantly lower in comparison with the lidocaine group. It may be due to release of endorphin, musculoskeletal relaxation and better cooperation of women during perineal suturing in the intervention group.

The power of this study was the detection of perineal pain just during episiotomy repair and just for primiparous participants. This can help us to arrive at a meaningful conclusion on the effect of $\mathrm{N}_{2} \mathrm{O}$ on pain alleviation during episiotomy suturing.

The present study had some limitations that were out of control of the study as follows: The midwife who performed the episiotomy was aware of analgesic method and so were the participants. In addition, the pain threshold was different in the participants (difference in expressing pain and its effect on final evaluation) and so were the women's response to pain intensity. Although the visual analog scale was used in the majority of studies as a valid instrument for measurement of acute pain and also episiotomy pain, the research team suggest performing further randomized studies using other pain measurement scales.

\section{Conclusion}

This study shows probable improvement in episiotomy analgesia due to $\mathrm{N}_{2} \mathrm{O}$ inhalation in terms of both maternal pain reduction and satisfaction.

\section{Conflict of Interests}

The authors declared no conflict of interest.

\section{Ethical Issues}

This study was approved by the ethics committee of Ahvaz Jundishapur University of Medical Sciences (No. .IR.AJUMS.REC.1394.151 5.6.2015). The protocol of the study was registered in the Iranian Registry for Randomized Controlled Trials website (identifier: IRCT2015062222874N1). The goals of the study were explained to mothers and informed consent was signed by each participant. They could withdraw at any time during 
the research.

\section{Financial Support}

This research article is extracted from a master's thesis (No. IR.AJUMS.REC.1394.151 5.6.2015). Financial support was provided by Ahvaz Jundishapur University of Medical Sciences.

\section{References}

1. Smith LA, Price N, Simonite V, Burns EE. Incidence of and risk factors for perineal trauma: a prospective observational study. BMC Pregnancy Childbirth. 2013;13:59. doi:10.1186/1471-2393-13-59.

2. Graham ID, Carroli G, Davies C, Medves JM. Episiotomy rates around the world: an update. Birth. 2005;32(3):219223. doi:10.1111/j.0730-7659.2005.00373.x.

3. Dahlen H, Homer C. Perineal trauma and postpartum perineal morbidity in Asian and non-Asian primiparous women giving birth in Australia. J Obstet Gynecol Neonatal Nurs. 2008;37(4):455-463. doi:10.1111/j.15526909.2008.00259.x.

4. Meng QT, Xia ZY, Liu J, Bayliss DA, Chen X. Local anesthetic inhibits hyperpolarization-activated cationic currents. Mol Pharmacol. 2011;79(5):866-873. doi:10.1124/ mol.110.070227.

5. Philipson EH, Kuhnert BR, Syracuse CD. Maternal, fetal, and neonatal lidocaine levels following local perineal infiltration. Am J Obstet Gynecol. 1984;149(4):403-407.

6. Becker DE, Rosenberg M. Nitrous oxide and the inhalation anesthetics. Anesth Prog. 2008;55(4):124-130; quiz 131122. doi:10.2344/0003-3006-55.4.124.

7. Emmanouil DE, Quock RM. Advances in understanding the actions of nitrous oxide. Anesth Prog. 2007;54(1):9-18. doi:10.2344/0003-3006(2007)54[9:aiutao]2.0.co;2.

8. Rosen MA. Nitrous oxide for relief of labor pain: a systematic review. Am J Obstet Gynecol. 2002;186(5 Suppl Nature):S110-126.

9. Mahshidfar B, Asgari-Darian A, Ghafouri HB, Ersoy G, Yasinzadeh MR. Reduction of anterior shoulder dislocation in emergency department; is entonox $((\mathrm{R}))$ effective? Bioimpacts. 2011;1(4):237-240. doi:10.5681/bi.2011.034.

10. Zacny JP, Lichtor JL, Coalson DW, Apfelbaum JL, Flemming D, Foster V. Time course of effects of brief inhalations of nitrous oxide in normal volunteers. Addiction. 1994;89(7):831-839.

11. 11.Sheikhan F, Jahdi F, Khoie EM, et al. Episiotomy discomforts relief using cold gel pads in primiparaus Iranian women (a comparative study). Res J Med Sci. 2011;5(3):150-154. doi: 10.3923/rjmsci.2011.150.154

12. Suhrabi Z, Taghinejad H. A comparative study on the efficacy of Ibuprofen and celecoxib on the intensity of perineal pain following episiotomy: a randomized clinical trial. Iran Red Crescent Med J. 2013;15(12):e9980. doi:10.5812/ircmj.9980.

13. Mohammadi A, Mohammad-Alizadeh-Charandabi S, Mirghafourvand M, Javadzadeh Y, Fardiazar Z, EffatiDaryani F. Effects of cinnamon on perineal pain and healing of episiotomy: a randomized placebo-controlled trial. J Integr Med. 2014;12(4):359-366. doi:10.1016/s20954964(14)60025-x.

14. Sanders J, Campbell R, Peters TJ. Effectiveness of pain relief during perineal suturing. Bjog. 2002;109(9):1066-1068.

15. Bodian CA, Freedman G, Hossain S, Eisenkraft JB, Beilin $Y$. The visual analog scale for pain: clinical significance in postoperative patients. Anesthesiology. 2001;95(6):13561361.

16. Pasha H, Basirat Z, Hajahmadi M, Bakhtiari A, Faramarzi M, Salmalian H. Maternal expectations and experiences of labor analgesia with nitrous oxide. Iran Red Crescent Med J. 2012;14(12):792-797. doi:10.5812/ircmj.3470.

17. Collins MR, Starr SA, Bishop JT, Baysinger CL. Nitrous oxide for labor analgesia: expanding analgesic options for women in the United States. Rev Obstet Gynecol. 2012;5(34):e126-131.

18. Kindberg S, Klunder L, Strom J, Henriksen TB. Ear acupuncture or local anaesthetics as pain relief during postpartum surgical repair: a randomised controlled trial. Bjog. 2009;116(4):569-576. doi:10.1111/j.14710528.2008.02016.x.

19. Berlit S, Tuschy B, Brade J, Mayer J, Kehl S, Sutterlin M. Effectiveness of nitrous oxide for postpartum perineal repair: a randomised controlled trial. Eur J Obstet Gynecol Reprod Biol. 2013;170(2):329-332. doi:10.1016/j. ejogrb.2013.06.025.

20. Franchi M, Cromi A, Scarperi S, Gaudino F, Siesto G, Ghezzi F. Comparison between lidocaine-prilocaine cream (EMLA) and mepivacaine infiltration for pain relief during perineal repair after childbirth: a randomized trial. Am J Obstet Gynecol. 2009;201(2):186.e181-185. doi:10.1016/j. ajog.2009.04.023.

21. Edwards A. Nursing \& Health Survival Guide: Labour Midwifery Skills. Pearson UK; 2012.

22. 22. Faddy SC, Garlick SR. A systematic review of the safety of analgesia with $50 \%$ nitrous oxide: can lay responders use analgesic gases in the prehospital setting? Emerg Med J. 2005;22(12):901-908. doi:10.1136/emj.2004.020891.

23. 23. Gutton C, Bellefleur JP, Puppo S, et al. Lidocaine versus ropivacaine for perineal infiltration post-episiotomy. Int J Gynaecol Obstet. 2013;122(1):33-36. doi:10.1016/j. ijgo.2013.01.028.

24. Klomp T, van Poppel M, Jones L, Lazet J, Di Nisio M, Lagro-Janssen AL. Inhaled analgesia for pain management in labour. Cochrane Database Syst Rev. 2012(9):Cd009351. doi:10.1002/14651858.CD009351.pub2.

25. Talebi H, Nourozi A, Jamilian M, Baharfar N, EghtesadiAraghi P. Entonox for labor pain: a randomized placebo controlled trial. Pak J Biol Sci. 2009;12(17):1217-1221.

Copyright ( 2017 The Author (s); This is an open-access article distributed under the terms of the Creative Commons Attribution License (http://creativecommons.org/licenses/by/4.0), which permits unrestricted use, distribution, and reproduction in any medium, provided the original work is properly cited. 